William R. Wiley

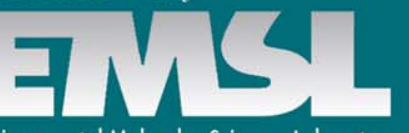

Environmental Molecular Sciences Laboratory
A Computational Approach to Understanding Aerosol Formation and Oxidant Chemistry in the Troposphere

April 2006

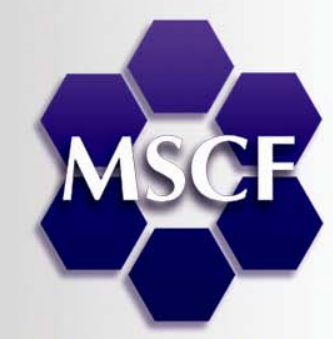

Computing Facility 
This research was performed in part using the Molecular Science Computing Facility (MSCF) in the William R. Wiley Environmental Molecular Sciences Laboratory, a national scientific user facility sponsored by the U.S. Department of Energy's Office of Biological and Environmental Research and located at the Pacific Northwest National Laboratory. Pacific Northwest is operated for the Department of Energy by Battelle.

\title{
DISCLAIMER
}

This report was prepared as an account of work sponsored by an agency of the United States Government. Neither the United States Government nor any agency thereof, nor Battelle Memorial Institute, nor any of their employees, makes any warranty, express or implied, or assumes any legal liability or responsibility for the accuracy, completeness, or usefulness of any information, apparatus, product, or process disclosed, or represents that its use would not infringe privately owned rights. Reference herein to any specific commercial product, process, or service by trade name, trademark, manufacturer, or otherwise does not necessarily constitute or imply its endorsement, recommendation, or favoring by the United States Government or any agency thereof, or Battelle Memorial Institute. The views and opinions of authors expressed herein do not necessarily state or reflect those of the United States Government or any agency thereof.

\author{
PACIFIC NORTHWEST NATIONAL LABORATORY \\ operated by \\ BATTELLE \\ for the \\ UNITED STATES DEPARTMENT OF ENERGY \\ under Contract DE-AC05-76RL01830
}

PNNL-15772 


\section{A Computational Approach to Understanding Aerosol Formation and Oxidant Chemistry in the Troposphere}

$\begin{array}{ll}\text { J.S. Francisco } & \text { D.A. Dixon } \\ \text { S.M. Kathmann } & \text { R. Bianco } \\ \text { G.K. Schenter } & \text { S. Wang } \\ \text { L.X. Dang } & \text { J.T. Hynes } \\ \text { S.S. Xantheas } & \text { A. Morita } \\ \text { B.C. Garrett } & \text { K.A. Peterson } \\ \text { S. Du } & \end{array}$

April 2006

Published by Pacific Northwest National Laboratory for the Environmental Molecular Sciences Laboratory 


\begin{abstract}
$\underline{\text { Abstract }}$
An understanding of the mechanisms and kinetics of aerosol formation and ozone production in the troposphere is currently a high priority because these phenomena are recognized as two major effects of energy-related air pollution. Atmospheric aerosols are of concern because of their effect on visibility, climate, and human health. Equally important, aerosols can change the chemistry of the atmosphere, in dramatic fashion, by providing new chemical pathways (in the condensed phase) unavailable in the gas phase. The oxidation of volatile organic compounds (VOCs) and inorganic compounds (e.g., sulfuric acid, ammonia, nitric acid, ions, and mineral) can produce precursor molecules that act as nucleation seeds.
\end{abstract}

The U.S. Department of Energy (DOE) Atmospheric Chemistry Program (ACP) has identified the need to evaluate the causes of variations in tropospheric aerosol chemical composition and concentrations, including determining the sources of aerosol particles and the fraction of such that are of primary and secondary origin. In particular, the ACP has called for a deeper understanding into aerosol formation because nucleation creates substantial concentrations of fresh particles that, via growth and coagulation, influence the Earth's radiation budget. Tropospheric ozone is also of concern primarily because of its impact on human health. Ozone levels are controlled by $\mathrm{NO}_{\mathrm{x}}$ and by VOCs in the lower troposphere. The VOCs can be either from natural emissions from such sources as vegetation and phytoplankton or from anthropogenic sources such as automobiles and oil-fueled power production plants. The major oxidant for VOCs in the atmosphere is the $\mathrm{OH}$ radical. With the increase in VOC emissions, there is rising concern regarding the available abundance of $\mathrm{HO}_{\mathrm{x}}$ species needed to initiate oxidation. Over the last five years, there have been four field studies aimed at initial measurements of $\mathrm{HO}_{\mathrm{x}}$ species $(\mathrm{OH}$ and $\mathrm{HO}_{2}$ radicals). These measurements revealed $\mathrm{HO}_{\mathrm{x}}$ levels that are two to four times higher than expected from the commonly assumed primary sources. Such elevated abundances of $\mathrm{HO}_{\mathrm{x}}$ imply a more photochemically active troposphere than previously thought. This implies that rates of ozone formation in the lower region of the atmosphere and the oxidation of $\mathrm{SO}_{2}$ can be enhanced, thus promoting the formation of new aerosol properties.

Central to unraveling this chemistry is the ability to assess the photochemical product distributions resulting from the photodissociation of by-products of VOC oxidation. We propose to use state-of-the-art theoretical techniques to develop a detailed understanding of the mechanisms of aerosol formation in multicomponent (mixed chemical) systems and the photochemistry of atmospheric organic species. The aerosol studies involve an approach that determines homogeneous gas-particle nucleation rates from knowledge of the molecular interactions that are used to define properties of molecular clusters. Over the past several years we developed Dynamical Nucleation Theory (DNT), a novel advance in the theoretical description of homogeneous gas-liquid nucleation, and applied it to gas-liquid nucleation of a single component system (e.g., water). The goal of the present research is to build upon these advances by extending the theory to multicomponent systems important in the atmosphere (such as clusters containing sulfuric acid, water, ions, ammonia, and organics). In addition, high-level $a b$ initio electronic structure calculations will be used to unravel the chemical reactivity of the $\mathrm{OH}$ radical and water clusters. 


\section{$\underline{\text { Research Team Leader and Members }}$}

\section{Team Leader}

Name:

Joseph S. Francisco

Position:

Department of Chemistry

Institution:

Purdue University

Address:

West Lafayette, IN 47907

Funding Source:

NSF, Atmospheric Chemistry Grant

Team Member 2

Name:

Shawn M. Kathmann

Position:

Molecular Interactions and Transformations Group

Institution:

Address:

Pacific Northwest National Laboratory

Funding Source:

Richland, WA 99352

LDRD CS\&E Project, “A Molecular-Level Description and Sensitivity Analysis for Improved Modeling of Aerosol Nucleation and Growth in Global Climate Models"

Team Member 3

Name:

Gregory K. Schenter

Position:

Molecular Interactions and Transformations Group

Institution:

Pacific Northwest National Laboratory

Address:

Richland, WA 99352

Funding Source:

DOE/BES/Chemical Sciences

\section{Team Member 4}

Name:

Liem X. Dang

Position:

Molecular Interactions and Transformations Group

Institution:

Address:

Pacific Northwest National Laboratory

Funding Source:

Richland, WA 99352

DOE/BES/Chemical Sciences

\section{Team Member 5}

Name:

Sotiris S. Xantheas

Position:

Molecular Interactions and Transformations Group

Institution:

Pacific Northwest National Laboratory

Address:

Richland, WA 99352

Funding Source:

DOE/BES/Chemical Sciences

Team Member 6

Name:

Bruce C. Garrett

Position:

Molecular Interactions and Transformations Group

Institution:

Pacific Northwest National Laboratory

Address:

Richland, WA 99352

Funding Source:

DOE/BES/Chemical Sciences 
Team Member 7

Name:

Shiyu Du

Position:

Department of Chemistry

Institution:

Purdue University

Address:

West Lafayette, IN 47907

Funding Source:

NSF, Atmospheric Chemistry Grant

\section{Team Member 8}

Name:

David A. Dixon

Position:

Battelle Fellow

Institution:

University of Alabama

Address:

Tuscaloosa, AL 35487

Funding Source:

U.S. Department of Energy

Team Member 9

Name:

Roberto Bianco

Position:

Department of Chemistry and Biochemistry

Institution:

University of Colorado

Address:

Boulder, CO 80309

Funding Source:

NSF, Atmospheric Chemistry Grant ATM-9613802

\section{Team Member 10}

Name:

Shuzhi Wang

Position:

Department of Chemistry and Biochemistry

Institution:

University of Colorado

Address:

Boulder, CO 80309

Funding Source:

NSF, Atmospheric Chemistry Grant ATM-9613802

\section{Team Member 11}

Name:

James T. Hynes

Position:

Department of Chemistry and Biochemistry

Institution:

University of Colorado

Address:

Boulder, CO 80309

Funding Source:

NSF, Atmospheric Chemistry Grant ATM-9613802

Team Member 12

Name:

Akihiro Morita

Position:

Institute for Molecular Science

Institution:

Myodaiji

Address:

Okazaki 444-8585, Japan

Team Member 13

Name:

Kirk A. Peterson

Position:

Department of Chemistry

Institution:

Washington State University

Address:

Pullman, Washington 99164

Funding Source:

NSF, Chemistry Grant CHE-0111282 


\section{Number of hours allocated}

FY03 and FY04: 900,000 hours on NWmpp2

\section{Number of hours actually used}

FY03 and FY04: 900,000 hours on NWmpp2

\section{Overview of the past year's accomplishments and activities}

The primary efforts undertaken on this project were:

1. Calculate accurate $a b$ initio energetics for several low-lying isomers within each of the four major families of minima of $\left(\mathrm{H}_{2} \mathrm{O}\right)_{20}$. Certain conformations of these clusters have been invoked to explain aerosol interfacial reactions with atmospheric $\mathrm{HO}_{2}(\mathrm{SSX})$.

2. Develop interaction potentials for sulfuric acid and water using $a b$ initio and experimental data. Sulfuric acid is an important nucleation seed in many gas-particle conversion processes (SMK, KAP, GKS, BCG).

3. Calculate interaction energies and thermodynamic properties for aqueous clusters with sulfuric acid, ions, organics, etc. (SMK, GKS, LXD, BCG).

4. Determine the nature of ion sign and size preference for small aqueous ionic clusters (SMK, GKS, BCG).

5. Investigate reaction mechanisms and thermodynamics within/on supercooled aqueous sulfate aerosol. In ongoing efforts, we are focusing on the structure and speciation of these strongly acidic substrates and their ability to catalyze heterogeneous reactions of halide species important for ozone depletion. (JTH, RB, AM)

6. Calculate accurate reaction energetics between $\mathrm{OH}$ and $\mathrm{H}_{2} \mathrm{O}$. These reaction energetics are important since $\mathrm{OH}$ removal mechanisms may occur via heterogeneous uptake at aqueous interfaces and thereby influence atmospheric $\mathrm{OH}$ abundance (JSF, BCG)

Overviews of these topics follow.

\section{$\underline{A b}$ Initio Calculations of $\left(\mathbf{H}_{2} \underline{O}\right)_{20} \underline{\text { Minima }}$}

Accurate energetics from high-level electronic structure calculations for several low-lying isomers within each of the four major families of minima (Wales and Hodges 1998) of $\left(\mathrm{H}_{2} \mathrm{O}\right)_{20}$ have been determined. Interest in the relative stabilities of these neutral clusters stems from the following important factors:

- Oftentimes the information used in the parameterization of a water empirical model is limited to either clusters of the first few molecules (e.g., AMOEBA [Ren and Ponder 2003], TTM family potentials [Burnham et al. 1999; Burnham and Xantheas 2002a, 2002b]) or properties of the condensed phase (e.g., SPC/E [Berendsen et al. 1987]). The question naturally arises of how these models perform for configurational regimes that were not used in the training set for their fitting. 
- The accurate determination of the relative stabilities of the various networks that are present for this cluster range is important for understanding the transition from the open 3-fold to the compact 4-fold coordinated structures.

- The experimentally observed pronounced magic number of $\mathrm{H}_{3} \mathrm{O}^{+}\left(\mathrm{H}_{2} \mathrm{O}\right)_{20}$ has been interpreted as a clathrate-like pentagonal dodecahedral structure. Previous theoretical studies have been in disagreement regarding to the relative stability of the various hydrogen bonded networks. However the structure of this cluster has not yet been directly determined experimentally.

- Clusters of this size can provide rational models to study processes occurring in the Earth's atmosphere. In a recent study (Shi et al. 2003) a specific arrangement of the $\left(\mathrm{H}_{2} \mathrm{O}\right)_{20}$ cluster (dodecahedral) was used as a crude model of the interface in order to investigate the interaction between $\mathrm{H}_{2} \mathrm{O}$ and a cloud droplet. Our results (vide infra) suggest that this network is not energetically favorable and, as a consequence, is not abundant under atmospheric conditions.

Wales and Hodges (1998) have previously identified four major families of minima for $\left(\mathrm{H}_{2} \mathrm{O}\right)_{20}$, which, based on the arrangement of the oxygen atom network, they classified as 1) dodecahedron, 2) fused cubes, 3) face-sharing pentagonal prisms and 4) edge-sharing pentagonal prisms. Representative candidates of these families of minima, the notation of which will be adopted throughout this study, are illustrated in Figure 1. It should be mentioned, however, that for similar arrangements of the oxygen atom network there exists a multitude of arrangements of the hydrogen atoms in a manner consistent of the ice rules (Hobbs 1974; Petrenko and Whitworth 1999). For instance, just for the dodecahedral arrangement of the oxygen atom network in $\left(\mathrm{H}_{2} \mathrm{O}\right)_{20}$, the application of graph theoretical techniques (McDonald et al. 1998; Kuo et al. 2001) yields an estimate of 30,026 symmetry-distinct hydrogen bond topologies which are likely candidates for local minimum structures. Several theoretical studies using empirical, semi-empirical models, and ab initio methods have arrived at different conclusions for the relative stability of the four major families. The empirical potentials TIP3P, TIP4P, TTM2-F, TTM2-R, ASP-W4, show that the edge-sharing pentagonal prism structure is energetically favorable, while the POL1 and SR predict a distorted edge-sharing and a face-sharing structure respectively, as the most stable conformation of $\left(\mathrm{H}_{2} \mathrm{O}\right)_{20}$. Semi-empirical electronic structure calculations based on the Intermediate Neglect of Differential Overlap (INDO) approximation have proposed a dodecahedral arrangement of the molecules (Khan 1995). Car-Parrinello calculations using ultrasoft pseudopotentials yielded a structure resembling a bulk-like arrangement with 4-fold coordinated molecules (Laasonen and Klein 1994). $A b$ initio calculations in the Hartree-Fock and Møller-Plesset second order (MP2) levels have suggested the edge-sharing pentagonal prism conformation as the most stable (Maheshwary et al. 2001; Day et al. 2000). However, due to the small size of the basis sets that have been used in these studies, no definitive conclusions could be made as to the binding energies reported that lie between -248.3 and $-151.10 \mathrm{kcal} / \mathrm{mol}$. 


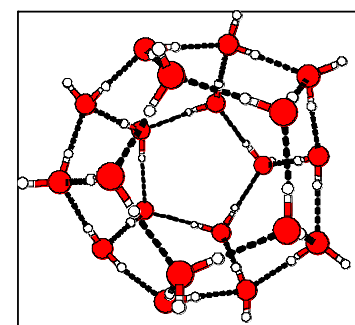

(a)

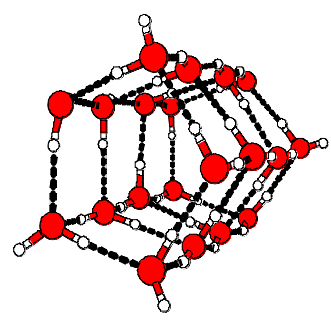

(c)

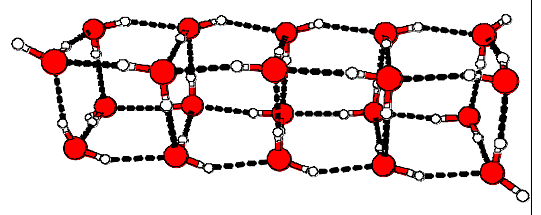

(b)

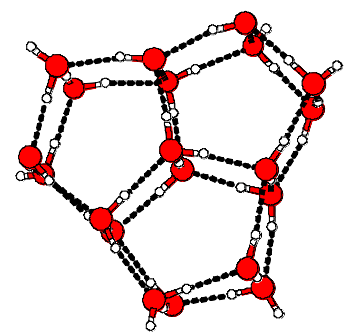

(d)

Figure 1. Representative candidates of the four major families of minima for $\left(\mathrm{H}_{2} \mathrm{O}\right)_{20}$ :

(a) dodecahedron, (b) fused cubes, (c) face-sharing pentagonal prisms, (d) edge-sharing pentagonal prisms.

From the above discussion it is evident that the lowest energy conformation of the $\left(\mathrm{H}_{2} \mathrm{O}\right)_{20}$ cluster is still controversial. In the absence of experimental determination of the structure and binding energy of $\left(\mathrm{H}_{2} \mathrm{O}\right)_{20}$, high-level $a b$ initio electronic structure calculations currently represent the only alternative to obtain this information. The focus of this work is to 1) establish reliable benchmarks for the energetics of the four major families of isomers for this cluster, 2) assess the accuracy of empirical interaction potentials for water, parametrized from molecular level information and including many-body effects, in reproducing the $a b$ initio results, and 3) obtain the vibrational spectra for the lowest energy structure of each family as a means for their future experimental assignment.

\section{Approach}

Full geometry optimization using the MP2 perturbation theory with the aug-cc-pVDZ basis set was performed for five to six structures of each of the four major families of $\left(\mathrm{H}_{2} \mathrm{O}\right)_{20}$. As initial guesses in this procedure, the lowest energy structures predicted from the TTM2-F and TIP4P empirical potentials were used. The most stable conformation of each family at the MP2/aug-cc-pVDZ level was re-optimized with the aug-cc-pVTZ basis set and a single-point energy calculation with the aug-cc-pVQZ set was performed. Based on these calculations, the energies at the MP2 complete basis set (CBS) limit for the most stable structure of each family were estimated. Finally, for these structures, the vibrational infrared (IR) spectra were calculated at the MP2 level of theory with the aug-cc-pVDZ basis set.

All calculations were carried out using the NWChem suite of codes (Straatsma et al. 2000) on phase 2 of the newly acquired massively parallel Hewlett-Packard supercomputer at the Molecular Science Computing Facility in the William R. Wiley Environmental Molecular Sciences Laboratory at Pacific Northwest National Laboratory (Kendall et al. 2002). The largest MP2 calculations for the lowest-lying isomers within each family were performed on 512 processors with the aug-cc-pVQZ basis set, which is 
comprised of the segmented contractions [5s4p3d2f1g]+(1s1p1d1f1g) for the Oxygen and [4s3p2d1f]+(1s1p1d1f) for the Hydrogen atoms, encompassing a total of 3440 contracted Gaussian basis functions.

\section{Results}

The variation of the MP2 binding energies for the lowest energy configuration within each family with basis set is shown in Figure 2. The relative energetic order of the most stable isomer of each family is predicted from the $a b$ initio calculations to be edge-sharing (most stable), face-sharing, fused cubes, and dodecahedron (less stable). The corresponding MP2/CBS binding energies are -217.9, -215.0, -212.6, and $-200.1 \mathrm{kcal} / \mathrm{mol}$, respectively.

The above first-principles results were compared to the predictions of the TTM2-F, TTM2-R AMOEBA, ASP-W4, and TIP4P empirical force-fields in an effort to assess their accuracy. It was found that, when compared with the other empirical potentials, the TTM2-F potential produces an overall better estimate of the absolute energetics of the four families. The absolute energetics of the first few minima within each family with the TTM2-F potential are compared to the MP2/CBS results, as shown in Figure 3. For all structures, the difference between the TTM2-F model and MP2/CBS results is $<1 \%$. In contrast, the other empirical potentials predict energies that differ by 3 to $5 \%$ from the ab initio values (Fanourgakis et al. 2004).

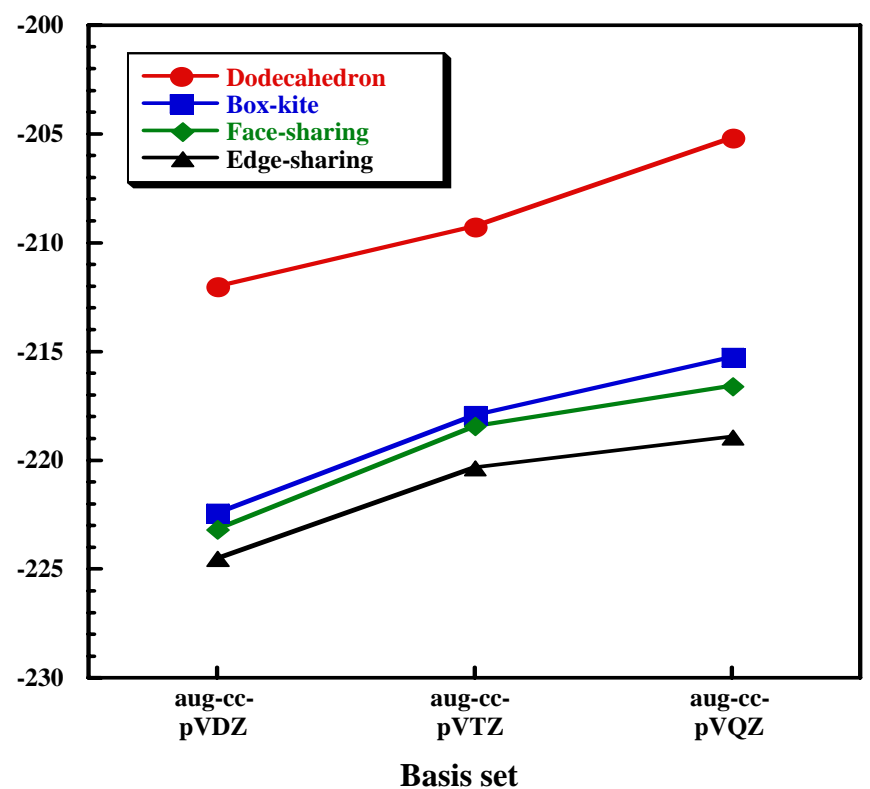

Figure 2. Variation of the MP2 binding energy with a basis set for the lowest energy structure within each of the four major families of minima of $\left(\mathrm{H}_{2} \mathrm{O}\right)_{20}$. 


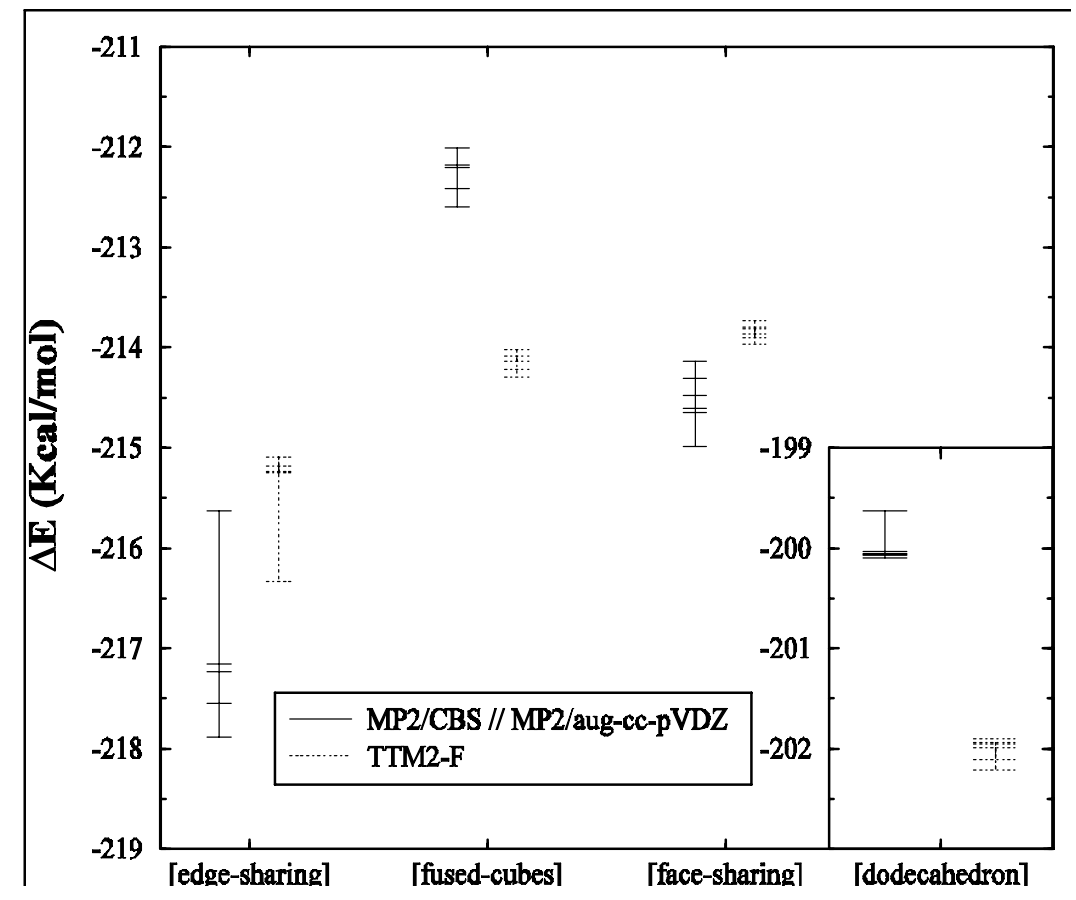

Figure 3. Comparison of the binding energies of low-lying isomers predicted by ab initio (solid-lines) and the TTM2-F potential (dashed lines) for the four families of $\left(\mathrm{H}_{2} \mathrm{O}\right)_{20}$.

The computed vibrational spectra for the most stable structure within each of the four families of $\left(\mathrm{H}_{2} \mathrm{O}\right)_{20}$ in the spectral range 3000 to $4000 \mathrm{~cm}^{-1}$ are shown in Figure 4. This spectral range is a fingerprint of the underlying hydrogen bonding network as it maps the "free" and "hydrogen-bonded" $\mathrm{OH}$ stretches. The red shift in the hydrogen-bonded frequencies is shown with respect to the average of the symmetric and antisymmetric water monomer frequencies, which is taken as the zero of the $x$-axis. It is evident that the arrangement of the hydrogen-bonding network, which is different between isomers of different families, affects significantly the frequencies and the IR intensities. As a result, each of the computed spectra appears to have different specific features in this spectral range. This information (Fanourgakis

et al. 2005) can provide the benchmark for future experimental structural assignment of $\left(\mathrm{H}_{2} \mathrm{O}\right)_{20}$ and its isomers formed either in molecular beams or inside helium droplets. 


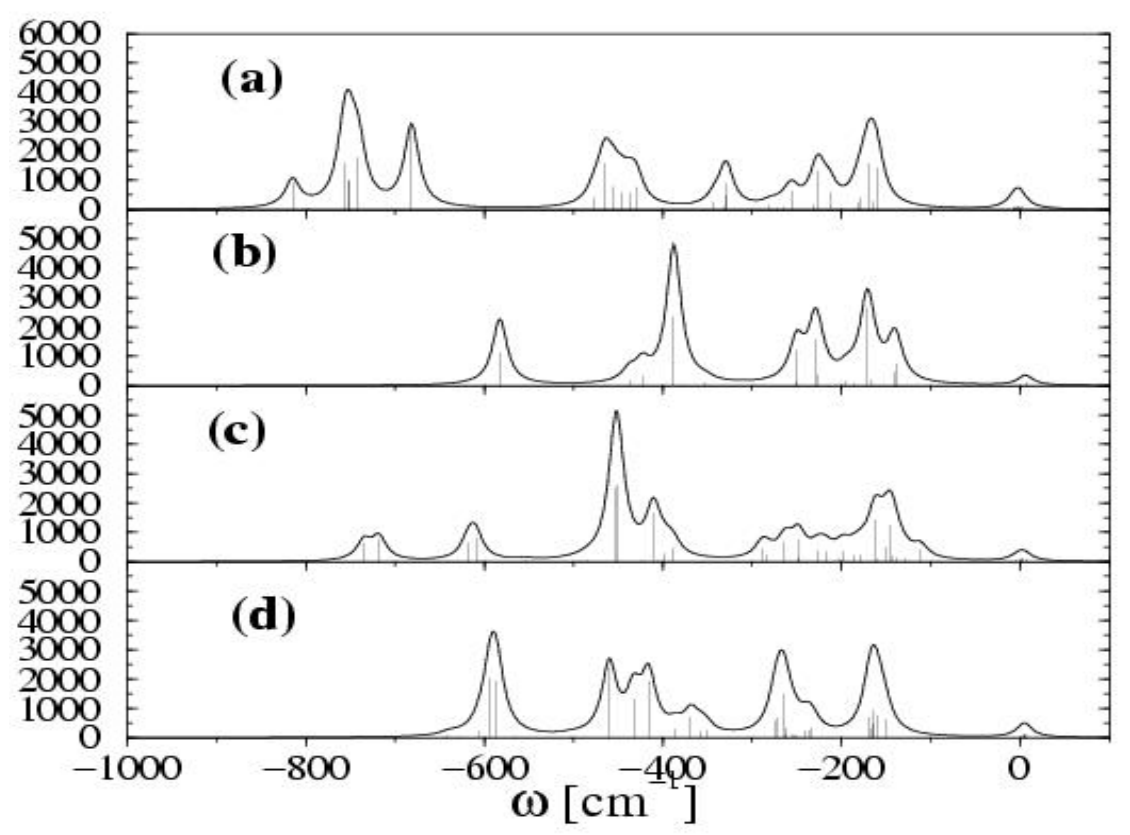

Figure 4. Computed vibrational spectra for the most stable isomer of each family. The zero frequency corresponds to the average frequency of the symmetric and antisymmetric stretch of the water monomer.

\section{References}

Berendsen, HJC, JR Grigera, and TP Straatsma. 1987. "The Missing Term in Effective Pair Potentials." Journal of Physical Chemistry (91:24) 6269-6271.

Burnham, CJ, J Li, SS Xantheas, and M Leslie. 1999. "The Parametrization of a Thole-Type All-Atom Polarizable Water Model from First Principles and Its Application to the Study of Water Clusters (N=2-21) and The Phonon Spectrum Of Ice Ih.” Journal of Chemical Physics (110:9) 4566-4581.

Burnham, CJ and SS Xantheas. 2002a. "Development of Transferable Interaction Models for Water. III. Reparametrization of an All-Atom Polarizable Rigid Model (TTM2-R) from First Principles." Journal of Chemical Physics (116) 1500-1510.

Burnham, CJ and SS Xantheas. 2002b. "Development of Transferable Interaction Models for Water. IV. A Flexible, All-Atom Polarizable Potential (TTM2-F) Based on Geometry Dependent Charges Derived from an Ab Initio Monomer Dipole Moment Surface." Journal of Chemical Physics (116:4) 5115-5124.

Day, PN, R Pachter, MS Gordon, and GN Merrill. 2000. "A Study of Water Clusters Using the Effective Fragment Potential and Monte Carlo Simulated Annealing." Journal of Chemical Physics (112:5) 2063-2073.

Fanourgakis, GS, E Aprá, and SS Xantheas. 2004. "High-Level Ab Initio Calculations for the Four Low-Lying Families of Minima Of $\left(\mathrm{H}_{2} \mathrm{O}\right)_{20}$. I. Estimates of MP2/CBS Binding Energies and Comparison with Empirical Potentials.” Journal of Chemical Physics (121:6) 2655-2663. 
Fanourgakis, GS, E Aprá, W Dejong, and SS Xantheas. 2005. "High-Level Ab Initio Calculations for the Four Low-Lying Families of Minima Of $\left(\mathrm{H}_{2} \mathrm{O}\right)_{20}$. II. Spectroscopic Signatures of the Dodecahedron, Fused Cubes, Face-Sharing Pentagonal Prisms, and Edge-Sharing Pentagonal Prisms Hydrogen Bonding Networks." Journal of Chemical Physics (122:13) 134304.

Hobbs, PV. 1974. Ice Physics. Clarendon Press, Oxford, New York.

Kendall RA, Apra E, Bernholdt DE, Bylaska EJ, Dupuis M, Fann GI, Harrison RJ, Ju JL, Nichols JA, Nieplocha J, Straatsma TP, Windus TL, and Wong AT. 2002. "High performance computational chemistry: An overview of NWChem a distributed parallel application." Computer Physics Communications 128 (1-2): 260-282.

Khan, A. 1995. "Examining the Cubic, Fused Cubic, and Cage Structures of $\left(\mathrm{H}_{2} \mathrm{O}\right)(\mathrm{N})$ for $\mathrm{N}=8,9,12$, 16, 20 and 21 - Do Fused Cubic Structures Form." Journal of Physical Chemistry (99:33) 12450-12455.

Kuo, JL, JV Coe, SJ Singer. 2001. "On the Use of Graph Invariants for Efficiently Generating Hydrogen Bond Topologies and Predicting Physical Properties of Water Clusters and Ice." Journal of Chemical Physics (114:6) 2527-2540.

Laasonen, K and ML Klein. 1994. "Structural Study of $\left(\mathrm{H}_{2} \mathrm{O}\right)_{20}$ and $\left(\mathrm{H}_{2} \mathrm{O}\right)_{21} \mathrm{H}+$ Using Density Functional Methods." Journal of Physical Chemistry (98:40) 10079-10083.

Maheshwary, S, Npatel, N Sathyamurthy, AD Kulkarni, and S Gadre. 2001. "Structure and Stability of Water Clusters $\left(\mathrm{H}_{2} \mathrm{O}\right) \mathrm{N}, \mathrm{N}=8$-20: An Ab Initio Investigation." Journal of Physical Chemistry A (105:46) 10525-10537.

McDonald, S, L Ojamäe, and SJ Singer. 1998. "Graph Theoretical Generation and Analysis of Hydrogen-Bonded Structures with Applications to the Neutral and Protonated Water Cube and Dodecahedral Clusters." Journal of Physical Chemistry A (102:17) 2824-2832.

Pacific Northwest National Laboratory (PNNL). 2002. "PNNL orders $\$ 24.5 \mathrm{M}$ supercomputer from Hewlett-Packard." PNNL press release, available online: http:/www.pnl.gov/news/2002/computer.htm

Petrenko, VF and RW Whitworth. 1999. Physics of Ice. Oxford University Press, New York.

Ren, P and JW Ponder. 2003. "Polarizable Atomic Multipole Water Model for Molecular Mechanics Simulation.” Journal of Physical Chemistry B (107) 5933-5947.

Shi, Q, SD Belair, JS Francisco, and S Kais. 2003. "On the Interactions Between Atmospheric Radicals and Cloud Droplets: A Molecular Picture of the Interface." Proceedings of the National Academy of Sciences of the United States of America (100:17) 9686-9690.

Straatsma, TP, RA Kendall, E Aprà, DE Bernholdt, EJ Bylaska, M Dupuis, GI Fann, RJ Harrison, J Ju, JA Nichols, J Nieplocha, TL Windus, and AT Wong. 2000. "NWChem, a Computational Chemistry Package for Parallel Computers, Version 4.5.” Comp. Phys. Comm. (128) 260.

Wales, DJ and MP Hodges. 1998. "Global Minima Of Water Clusters $\left(\mathrm{H}_{2} \mathrm{O}\right)_{\mathrm{n}}, \mathrm{n} \leq 21$, described by an Empirical Potential.” Chemical Physics Letters (286) 65-72. 


\section{$\underline{\text { Interaction Potential for Sulfuric Acid and Water }}$}

Calculation of nucleation rates with the framework of DNT requires three tasks: 1) development of accurate potential energy functions (PEFs), 2) Monte Carlo simulation to calculate the cluster Helmholtz free energies, 3) Monte Carlo simulation to determine evaporation and condensation rate constants, and 4) calculation of nucleation rates from solution of the kinetic equations. Accurate electronic structure data for the interactions of water with sulfuric acid are available and will be used to calibrate the potentials. In addition, we will examine the effects of changes in the PEFs on nucleation mechanisms and rates. The electronic structure information will provide the basis for making modifications to the PEFs. The ionwater potentials are chosen from the literature for comparison purposes. The water-water interaction in all the clusters is described by the well-known TIP4P interaction potential.

A potential model was developed over the past year to reproduce accurate structural and energetic properties for the sulfuric acid and water system. First, this interaction potential was designed with classical simulations in mind. Thus, the parameters of the potential were adjusted to yield agreement with the zero point corrected $a b$ initio binding energy (within the harmonic approximation) for the sulfuric acid monohydrate $\mathrm{H}_{2} \mathrm{SO}_{4} \bullet \mathrm{H}_{2} \mathrm{O}(-10.5 \mathrm{kcal} / \mathrm{mol})$ and sulfuric acid dimer $\mathrm{H}_{2} \mathrm{SO}_{4} \bullet \mathrm{H}_{2} \mathrm{SO}_{4}(-17.0 \mathrm{kcal} / \mathrm{mol})$. The intermolecular potential has the form

$$
U_{\text {inter }}=\sum_{i \neq j}\left\{\frac{k q_{i} q_{j}}{r_{i j}}+4 \varepsilon_{i j}\left[\left(\frac{\sigma_{i j}}{r_{i j}}\right)^{12}-\left(\frac{\sigma_{i j}}{r_{i j}}\right)^{6}\right]\right\}
$$

where the standard combination rules apply for the Lennard-Jones parameters. The intramolecular potential was parametrized using KAP's data (all MP2/aug-cc-pVQZ+d) on the energetics for the dihedral degrees of freedom using the form

$$
\begin{gathered}
U_{\text {intra }}=\sum_{\text {acid hydrogens }} c_{1} \exp \left[-c_{2}\left(\psi_{1}^{2}+\psi_{2}^{2}+c_{3} \psi_{1} \psi_{2}\right)\right]+c_{4}\left[1+\cos \left(c_{5} \psi_{1}\right)\right] \\
+c_{6}\left[1+\cos \left(c_{7} \psi_{2}\right)\right]+c_{8}\left[1+\cos \left(c_{9} \psi_{1} \psi_{2}\right)\right]+c_{10}
\end{gathered}
$$

where $\psi_{1}$ and $\psi_{2}$ are the two hydrogen dihedral angles $(\mathrm{O}-\mathrm{S}-\mathrm{O}-\mathrm{H})$ in $\mathrm{H}_{2} \mathrm{SO}_{4}$. The dihedral interaction potential is shown in Figure 5. Note that the peak in the middle of the surface corresponds to the case when both hydrogens are pointing at one another. 


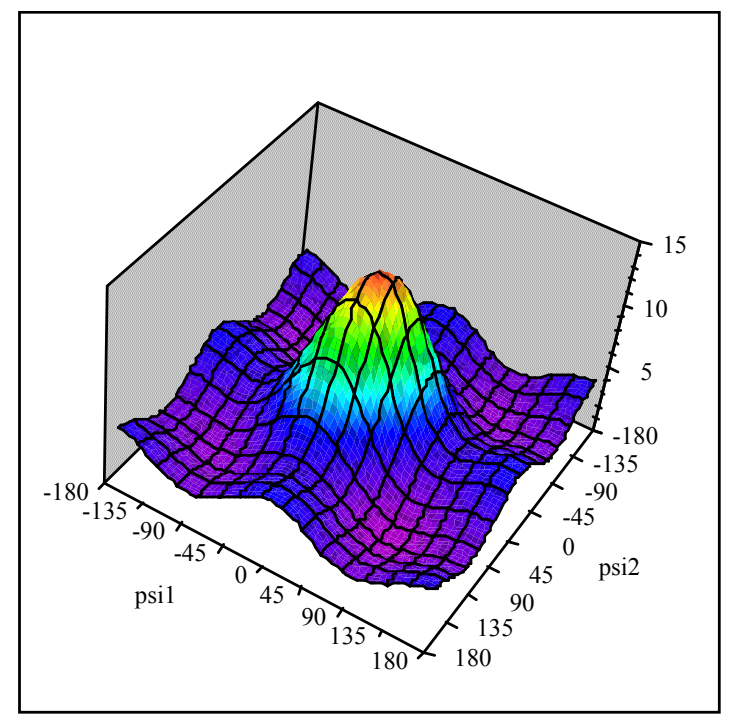

Figure 5. A 3-D plot of the intramolecular potential (in $\mathrm{kcal} / \mathrm{mol}$ ) for the two hydrogen dihedral angles (O-S-O-H) in the sulfuric acid molecule.

In order to assess the influence of zero point energy (ZPE) on cluster thermodynamic properties, we calculated the size-dependent chemical potentials of pure sulfuric acid and pure water clusters. For the water clusters, we use the TIP4P interaction potential, as it was parameterized to reproduce the bulk enthalpy of vaporization and density at $298 \mathrm{~K}$ and thus implicitly included ZPE effects. For the pure sulfuric acid clusters, we fit two acid-acid potentials: one with ZPE included and the other without ZPE included. In the case with ZPE included, the potential was fit to include the harmonic ZPE, giving a sulfuric acid dimer energy of $-17.0 \mathrm{kcal} / \mathrm{mol}$. Without $\mathrm{ZPE}$, the potential was fit to yield to the sulfuric acid dimer energy of $-18.3 \mathrm{kcal} / \mathrm{mol}$. The results (Figure 6) show the thermodynamic extrapolation of the chemical potentials back to the molecular limit as a function of cluster size to the minus $1 / 3$ power. The slope of the line (dashed line is black for water and blue for sulfuric acid) is proportionate to the surface tension, and the intercept is related to the equilibrium vapor pressure. Using this method, the computed chemical potentials for the clusters can be plotted and should approach the correct slope and intercept as a function of cluster size. It can be seen from Figure 6, the potential fit to the ZPE corrected dimer binding energy does a better job of reaching the proper limit as the clusters get larger. Whereas the sulfuric acid potential without ZPE included may yield a surface tension consistent with experiment, but the limiting intercept will deviate several $\mathrm{kcal} / \mathrm{mol}$ from the experimental vapor pressure of pure sulfuric acid at $298 \mathrm{~K}$. 


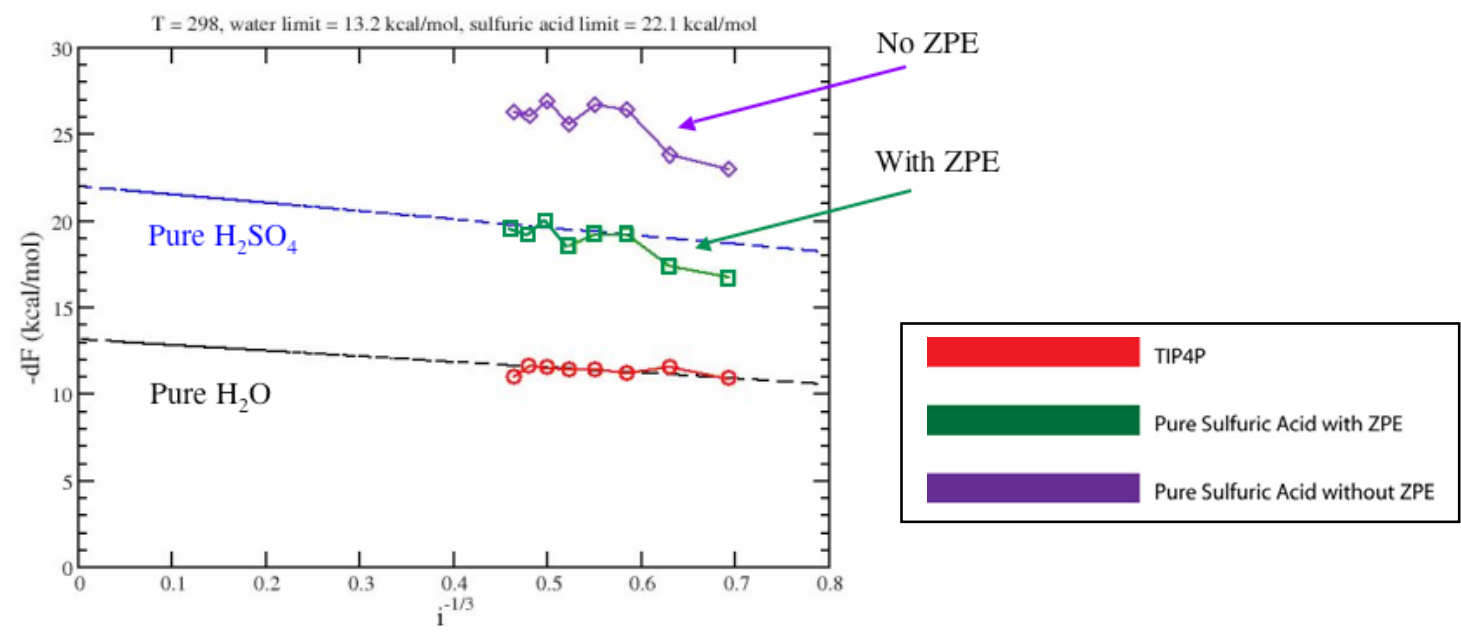

Figure 6. Plot of the negative of the chemical potentials for pure water.

\section{Interaction Energies for Aqueous Clusters}

Accurate electronic structure calculations have been performed for several molecular systems some of which are shown in Figure 7. The interaction energies and ZPEs obtained from these calculations are being used to develop representative PEFs. Comparing accurate interactions energies allows the identification of species that may act as favorable aqueous nucleation seeds. Some common atmospheric species that stabilize water clusters are: ions, sulfuric acid, and nitric acid. Recent observation has indicated that biogenic photo-oxidation by-products like pinonic and pinic acids may play key roles in secondary organic aerosol formation. Indeed, $a b$ initio calculations on pinic acid and water yield interaction energies similar to those between sulfuric acid and water.

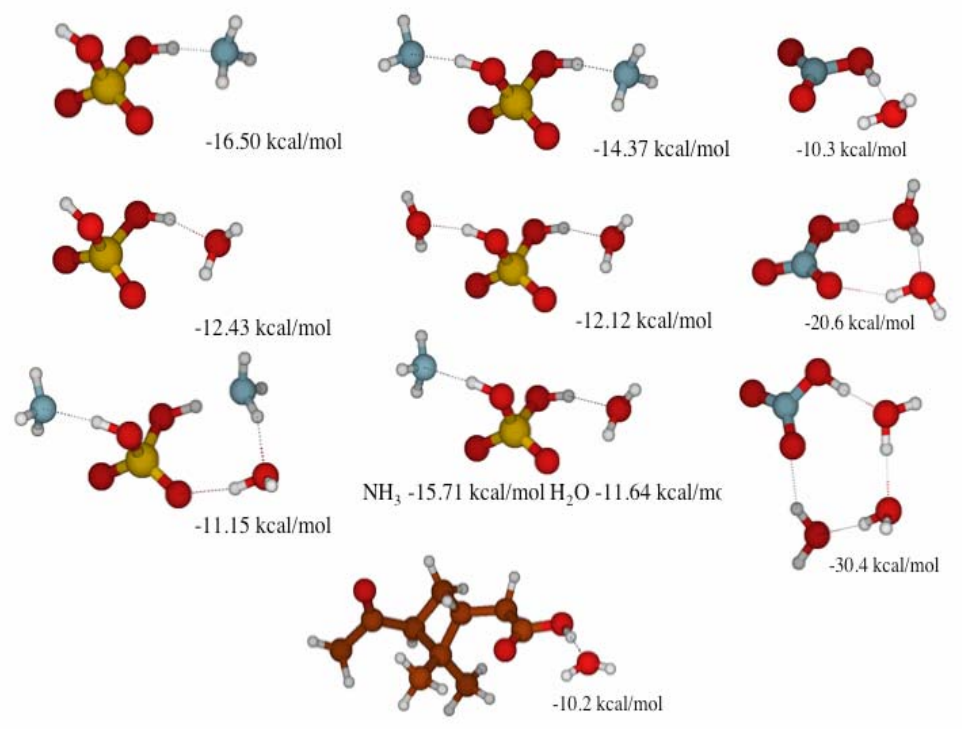

Figure 7. Some molecular clusters relevant to the atmosphere involving $\mathrm{H}_{2} \mathrm{SO}_{4}, \mathrm{H}_{2} \mathrm{O}, \mathrm{NH}_{3}, \mathrm{HNO}_{3}$, and pinic acid. These interaction energies do not include ZPE. 


\section{$\underline{\text { Nature of Ion Preference in Small Aqueous Ionic Clusters }}$}

Experiments have shown that ions can substantially increase vapor-liquid nucleation rates. However, interpretation of these experiments is complicated by ambiguities arising from the manner in which the ions are produced. Several studies have concluded that water has a general preference for anions over cations. We show that specification of ion's sign alone is insufficient to provide an understanding of the aqueous ionic cluster thermodynamics and that Classical Ion-Induced Nucleation Theory (CIINT) does not treat the cluster physics properly to describe ion-induced nucleation accurately.

Definitive experimental resolution of whether anions or cations enhance nucleation rates is difficult because it is not possible to simply change an ion's charge without altering its electronic structure and thus its chemical properties. Castleman and Tang (1972) stated over 30 years ago "the sign of the charge is not the only prerequisite and even ions of like sign may nucleate at different supersaturation ratios. The interpretation of the data obtained in most ion-nucleation experiments is therefore very uncertain and an appropriate account of the actual species is necessary in understanding the molecular nature of the nucleation phenomena." This statement is in stark contrast to the conclusion made by Katz et al. (1994) that "understanding the effect of ions would be very difficult, or even impossible, if the ions' specific chemical characteristics had a significant effect on their nucleating efficiency." Further underscoring the importance of chemistry, Castleman (1978) suggested, based on electron affinities and ionization potentials, that halides and metals would be appropriate primary negative and positive ions, respectively. Indeed, experimental data (Castleman 1978; Dzidic 1970) on ionic hydrates explicitly demonstrate the sensitivity of mono-hydration enthalpies on an ion's chemical identity (for example, $\mathrm{Li}+=-34.0, \mathrm{Na}+=$ 24.0, $\mathrm{K}+=-17.9, \mathrm{Rb}+=-15.9, \mathrm{Cs}+=-13.7, \mathrm{~F}-=-23.3, \mathrm{Cl}-=-13.1, \mathrm{Br}-=-12.6, \mathrm{I}-=-10.2$; all energies in $\mathrm{kcal} / \mathrm{mol})$.

Theoretical approaches offer a means of isolating different effects, such as the sign of the ionic charge, while keeping all other factors constant. The first theory of ion-induced nucleation modified the Classical Nucleation Theory (CNT), using the electrostatic models of Born (1920) and Thomson (1906) to yield the CIINT. The CIINT models cluster thermodynamics using the bulk liquid surface tension, density, and dielectric constant. Although CIINT does predict that ions have large effects on nucleation rates, it does not explicitly treat cluster chemical physics.

In this work, we use the TIP4P potential to describe water-water interactions and describe the ion-water interactions by Coulomb + Lennard-Jones (LJ) potentials. To study the dependence of the Helmholtz free energies on the ion (X) size and $\mathrm{q}_{\mathrm{X}}= \pm 1$, two sets of parameters are considered: small (SM) with LJ parameters $\sigma_{\mathrm{X}}=2.35 \AA, \varepsilon_{\mathrm{X}}=0.13 \mathrm{kcal} / \mathrm{mol}$ and large $(\mathrm{LG})$ with parameters $\sigma_{\mathrm{X}}=4.45 \AA, \varepsilon_{\mathrm{X}}=0.10$ $\mathrm{kcal} / \mathrm{mol}$ (the effect of the $0.03 \mathrm{kcal} / \mathrm{mol}$ difference in $\varepsilon_{X}$ parameters is negligible). It is well known that polarizability has an influence ion-cluster structure and energetics. We anticipate that ZPE effects will be just as important as polarization energy to the quantitative prediction of ion-induced nucleation rates. However, our focus here is on the more general features of ion-water interactions within a cluster and how simple chemical differences can amount to profound influences on cluster thermodynamics. For the sake of illustration, we identified an ion chemically simply by the sign of its charge and its effective size (Figures 8 and 9). 

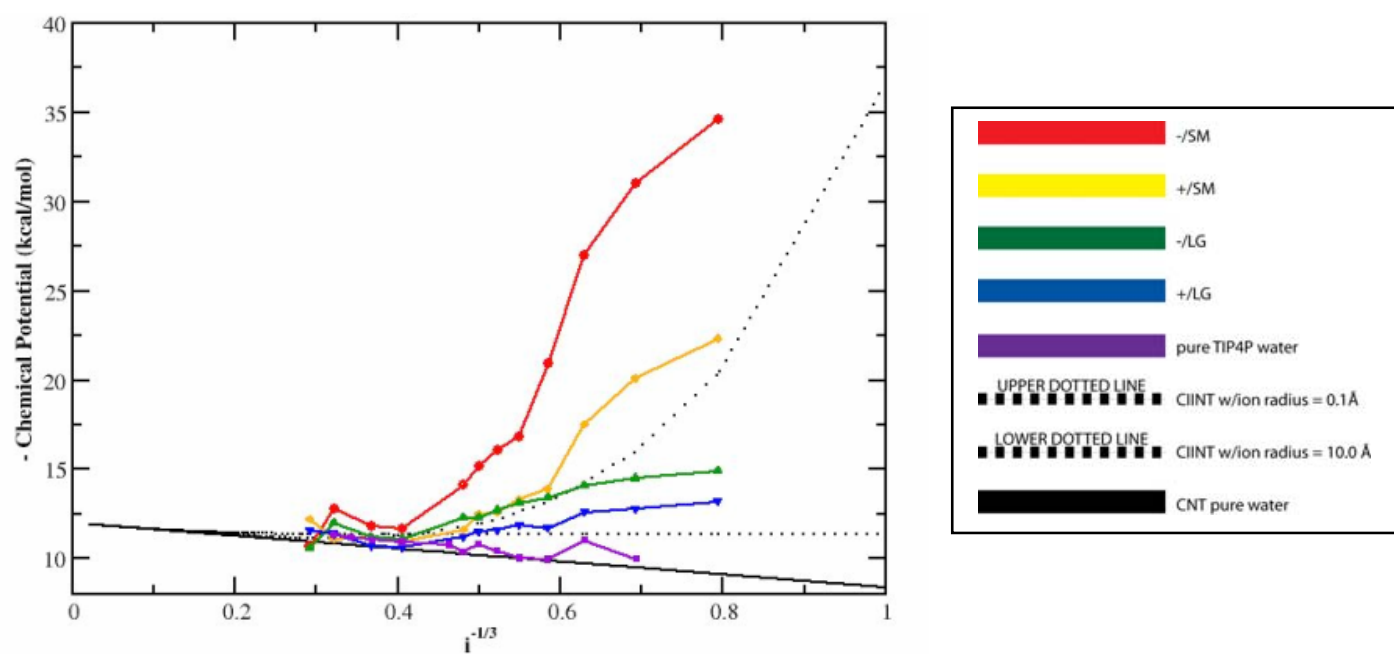

Figure 8. Size-dependent chemical potentials of aqueous ionic clusters using ions of different size $(2.35 \AA=\mathrm{SM}$ and $4.40 \AA=\mathrm{LG})$ and sign $(+/-)$.

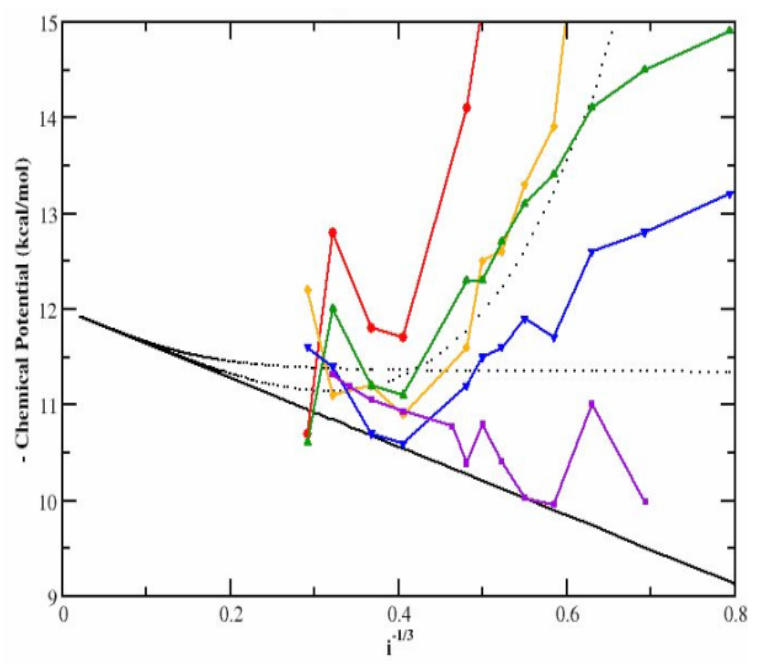

Figure 9. Expanded view of Figure 8 showing non-monotonic behavior of aqueous ionic cluster chemical potentials.

The results in Figure 8 show how the negative of the chemical potentials, for both SM/LG ions of \pm sign, vary with an increasing number of water molecules. Also plotted in Figure 8 is the CNT result for pure water and the CIINT results for the limiting cases for ionic clusters, where the lower (upper) dotted curve is for $r_{X}=10.0 \AA(0.1 \AA)$. These radii were chosen to cover a broad range so as to include radii typically used for atomic and molecular ions. In the molecular calculations, the LJ size parameter $\left(\sigma_{\mathrm{X}}\right)$ plays a similar role as $r_{X}$ in CIINT. The molecular calculations display a negative curvature for the SM anion and cation, whereas the CIINT shows the opposite behavior. Note also the large differences in chemical potentials predicted from the molecular calculations versus those from CIINT; some differences are as large as $20 \mathrm{kcal} / \mathrm{mol}$ in a single monomer addition step. Our previous sensitivity studies on nucleation found that tenths of a $\mathrm{kcal} / \mathrm{mol}$ in each mechanistic step can have profound consequences on the nucleation rate. It is seen from Figure 8 that for the same $\sigma_{\mathrm{X}}$, water prefers the atomic anion to the cation. However, for different effective sizes, this is not true. Some examples serve to highlight the essential 
features of our analysis: $\mathrm{H}_{2} \mathrm{O}$ prefers 1) a small cation to a large anion, 2) a small anion to a large anion, and 3) a small cation to a large cation. These findings can be understood by considering the trade-offs between attractive and repulsive ion-water interactions. The small ion $\left(\sigma_{X}=2.35 \AA\right)$ has a smaller repulsive core, allowing the water molecule to penetrate deeper into the Coulomb well, whereas the larger repulsive core ion $\left(\sigma_{\mathrm{X}}=4.45 \AA\right)$ does not allow water to sample the Coulomb well as deeply. For a given LJ size parameter, the side effect can be explained by noting that there is no core repulsion placed on water's H-atoms, allowing the hydrogen positive charge to get closer to the anion. These simple examples underscore the importance of the details of the chemistry of small aqueous ionic clusters relevant in ion-induced nucleation. Figure 9 shows at least two interesting features: 1) the cluster chemical potential size dependence is non-monotonic, and 2) the chemical potentials can cross each other. When the chemical potentials cross one another, this means the preference for the additional water molecule onto the $i-1$ cluster is reversed. Eventually, as water monomers are added to ionic clusters containing more water molecules, the chemical potential for the incoming water monomer should approach that for pure water clusters since the influence of the electric field of the screened ion will decrease with increasing cluster size. The insert shows that 40 water molecules are still not enough to reach this limit. Note also that the SM/LG anion chemical potentials and SM/LG cation chemical potentials track one another for the bigger clusters.

\section{References}

Born, M Z. 1920. "Volume and Heath Hydration of the Ions.” Zeitschrift fur Physik 1(1):45-48.

Castleman, AW, Jr, and IN Tang. 1972. "Role of Small Clusters in Nucleation about Ions." Journal of Chemical Physics 57(9):3629-3638.

Castleman, AW, Jr, PM Holland, and RG Keese. 1978. "The Properties of Ion Clusters and Their Relationship to Heteromolecular Nucleation." Journal of Chemical Physics 68(4):1760-1767.

Dzidic, I and P Kebarle. 1970. "Hydration of the Alkali Ions in the Gas Phse. Enthalpies and Entropies of Reactions of $\mathrm{M}^{+}\left(\mathrm{H}_{2} \mathrm{O}\right)_{n-1}+\mathrm{H}_{2} \mathrm{O}=\mathrm{M}^{+}\left(\mathrm{H}_{2} \mathrm{O}\right)_{n}$." Journal of Physical Chemistry 74(7):1466-1474, DOI: $10,1021 / \mathrm{j} 100702 \mathrm{a} 013$.

Katz JL, JA Fisk, and VM Chakarov. 1994. "Condensation of a Supersaturated Vapor IX. Nucleation on Ions.” Journal of Chemical Physics 101(3):2309-2318.

Thomson, JJ. 1906. Conduction of Electricity Through Gases. 2nd ed. Cambridge University Press, Cambridge, England.

\section{Supercooled Aqueous Sulfate Aerosol}

We are investigating the chemistry of sulfate aerosols, supercooled $(220 \mathrm{~K})$ aqueous solutions of sulfuric acid ranging from 50 to $80 \% \mathrm{wt} \mathrm{H}_{2} \mathrm{SO}_{4}$, by using theoretical methodologies. In ongoing efforts, we are focusing on the structure and speciation of these strongly acidic substrates, and on their ability to catalyze heterogeneous reactions of halide species important for ozone depletion.

A theoretical method for the Sum Frequency Generation (SFG) analysis of aqueous surfaces, based on molecular dynamics (MD) simulations, has been formulated and applied to liquid water, in view of its 
future application to sulfate aerosols. The simulated SFG spectrum of water reproduces the experimental one quite well. We have developed a Monte Carlo (MC) methodology for the simulation of protic systems, which takes into account both proton transfer and electronic polarizability. This methodology has been employed to simulate bulk samples of sulfuric acid tetrahydrate ( $58 \% \mathrm{wt})$ and dihydrate (73\%wt) at $300 \mathrm{~K}$. Preliminary results of MC simulations yield compositions consistent with those derived from thermodynamic models.

Several heterogeneous reactions on aqueous substrates including $\mathrm{H}_{2} \mathrm{SO}_{4}$, namely $\mathrm{HOX}+\mathrm{HCl} \rightarrow \mathrm{XCl}+$ $\mathrm{H}_{2} \mathrm{O}(\mathrm{X}=\mathrm{Cl}, \mathrm{Br}) \mathrm{HCl}+\mathrm{ClONO}_{2} \rightarrow \mathrm{Cl}_{2}+\mathrm{HNO}_{3}$, and $\mathrm{H}_{2} \mathrm{SO}_{4} \rightarrow \mathrm{HSO}_{4}{ }^{-}+\mathrm{H}_{3} \mathrm{O}^{+}$, important for midlatitude, stratospheric ozone depletion, have been modelled quantum chemically by using 1) a quantum chemical core reaction system comprising the reactants, $\mathrm{a}_{2} \mathrm{SO}_{4}$ molecule, and a few water molecules actively participating in the reaction via proton transfer, and 2) a hydrogen-bonded lattice of about 30 to 40 classical, polarizable waters in which the core reaction system is embedded. A preliminary step in our investigation has been the calculation of the energetics of the dissociation of $\mathrm{H}_{2} \mathrm{SO}_{4}$ at the surface of a water layer. The calculated reaction paths show mechanisms involving a nucleophilic attack coupled to proton transfer.

\section{Sum Frequency Generation (SFG) study of the surface of liquid water}

SFG spectroscopy is a powerful experimental technique to probe surface structures. The SFG spectrum of the water surface was theoretically analyzed in the $\mathrm{OH}$ stretch mode frequency region based on $a b$ initio molecular orbital theory and molecular dynamics simulation. The environmental effects on the normal modes of $\mathrm{OH}$ stretching vibration, their frequency shifts, and hyperpolarizability were formulated and tested. The simulated SFG spectrum reproduces experimental results quite well. The surface susceptibilities of the dangling bond and hydrogen-bonded bands have opposite signs in their imaginary parts, which indicates opposite $\mathrm{OH}$ directions at the surface associated with these bands. The former band turns out to be sensitive only to the top monolayer, and the latter band to a few top monolayers. Further analysis reveals that those two bands arise from quite different types of molecular orientations. The assignment of the SFG spectrum is also analyzed in terms of the symmetric/antisymmetric character of the $\mathrm{OH}$ stretching modes and the degree of mode delocalization (Morita and Hynes 2000).

We have devised a new theoretical mode of nonempirical analysis of SFG spectra for interfacial structures, which considerably generalizes our previous effort (Morita and Hynes 2002), which involved several empirical elements. The method is based on a time correlation function for the frequencydependent hyperpolarizability, which can be straightforwardly evaluated via MD simulations and which explicitly takes into account, for example, intramolecular vibrations and electronic polarization. The new theory is capable of precisely describing a number of factors significant for the spectrum, such as the dielectric local field correction, vibrational dephasing, and inter/intramolecular vibrational coupling, and is fairly nonempirical and rigorous, within the dipole approximation. The results for the water-vapor interface reproduce the experimental spectra fairly well, although with some discrepancies; possible reasons for these are suggested (Morita and Hynes 2002).

\section{Quantum chemical study of the dissociation of $\mathrm{H}_{2} \mathrm{SO}_{4}$ at aqueous surfaces}

A quantum chemical study on the ionic dissociation of sulfuric acid at the surface of an aqueous layer (Bianco and Hynes 2004) via the model system $\mathrm{H}_{2} \mathrm{SO}_{4} \cdot\left(\mathrm{H}_{2} \mathrm{O}\right)_{6} \rightarrow \mathrm{HSO}_{4}{ }^{-} \mathrm{H}_{3} \mathrm{O}^{+} \cdot\left(\mathrm{H}_{2} \mathrm{O}\right)_{5}$ embedded at the surface of a cluster of classical, polarizable waters has been extended to include two other possible 
orientations of the two H-bearing oxygens of a $\mathrm{H}_{2} \mathrm{SO}_{4}$ molecule embedded at the surface of a water layer: 1) both $\mathrm{OH}$ radicals lie at the surface, and 2) one $\mathrm{OH}$ lying at the surface while the other is pointing towards the bulk . In both cases, the acidic protons are hydrogen-bonded to water molecules. At $0 \mathrm{~K}$, case (1) showed the $\mathrm{OH}$ ionic dissociation to be endothermic by $\sim 3 \mathrm{kcal} / \mathrm{mol}$, whereas case (2), for the bulk $\mathrm{OH}$, yielded a reaction barrier $<1 \mathrm{kcal} / \mathrm{mol}(0.24 \mathrm{kcal} / \mathrm{mol})$ with an exothermicity of $\sim 8 \mathrm{kcal} / \mathrm{mol}$. These results suggest that the solvation shell of the water accepting the acidic proton is a determining factor in the dissociation of surface $\mathrm{H}_{2} \mathrm{SO}_{4}$.

\section{Quantum chemical study of the reaction $\mathrm{HOCl}+\mathrm{HCl} \rightarrow \mathrm{Cl}_{2}+\mathrm{H}_{2} \mathrm{O}$ catalyzed by $\mathrm{H}_{2} \mathrm{SO}_{4}$}

The reaction path has been found and the transition state indicates acid catalysis, with a proton transfer from $\mathrm{H}_{2} \mathrm{SO}_{4}$ to $\mathrm{HOCl}$ coupled to the nucleophilic attack of $\mathrm{Cl}^{-}$on $\mathrm{HOCl}$ (see Figure 10). The calculated barrier height of $7 \mathrm{kcal} / \mathrm{mol}$ at $0 \mathrm{~K}$ is consistent with those obtained from experiment: $6.5 \mathrm{kcal} / \mathrm{mol}$ $\left(\mathrm{T}=\mathrm{HOCl}+\mathrm{HCl} \rightarrow \mathrm{Cl}_{2}+\mathrm{H}_{2} \mathrm{O}\right.$ catalyzed by $\left.\mathrm{H}_{2} \mathrm{SO}_{4} 273-303 \mathrm{~K}\right)$ and $7 \mathrm{kcal} / \mathrm{mol}(\mathrm{T}=250 \mathrm{~K}$, protonation step) (Wang and Margerum 1994; Donaldson et al. 1997, respectively).
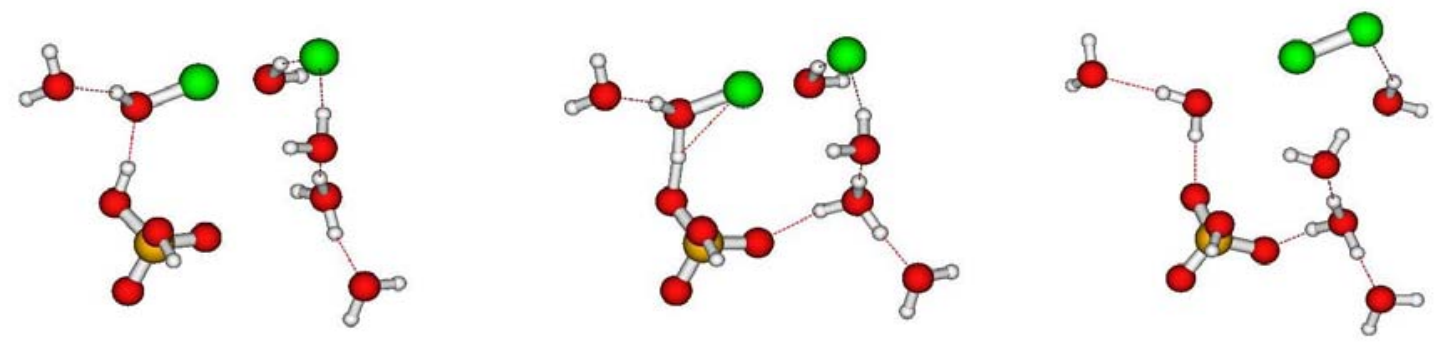

Figure 10. $\mathrm{HOCl}+\mathrm{HCl} \rightarrow \mathrm{Cl}_{2}+\mathrm{H}_{2} \mathrm{O}$ catalyzed by $\mathrm{H}_{2} \mathrm{SO}_{4}$. From left to right: reactant complex, transition state, and product complex.

\section{Quantum chemical study of the reaction $\mathrm{HOBr}+\mathrm{HCl} \rightarrow \mathrm{BrCl}+\mathrm{H}_{2} \mathrm{O}$ catalyzed by $\mathrm{H}_{2} \mathrm{SO}_{4}$}

The transition state of the reaction has been found. As in the $\mathrm{HOCl}+\mathrm{HCl}$ case above, the reaction mechanism for $\mathrm{HOBr}+\mathrm{HCl}$ involves the coupling between the proton transfer to the oxygen of $\mathrm{HOBr}$ and the nucleophilic attack of chloride ion on bromine. Reaction path calculations are in progress.

\section{Quantum chemical study of the reaction $\mathrm{ClONO}_{2}+\mathrm{HCl} \rightarrow \mathrm{Cl}_{2}+\mathrm{HNO}_{3}$ catalyzed by $\mathrm{H}_{2} \mathrm{SO}_{4}$}

In a model reaction system involving $\mathrm{ClONO}_{2}, \mathrm{HCl}$, and $\mathrm{H}_{2} \mathrm{SO}_{4}$ embedded in a cluster of water molecules, a transition state has been identified that shows nucleophilic attack by $\mathrm{Cl}^{-}$on $\mathrm{ClONO}_{2}$, without proton transfer from $\mathrm{H}_{2} \mathrm{SO}_{4}$ to the nitrate group, to which it was initially coordinated.

\section{Reactive Monte Carlo simulations of structure and speciation of sulfate aerosols}

A Monte Carlo methodology for the simulation of the equilibrium properties of reactive chemical systems (Johnson 1999 and references therein) has been extended to model the structure and speciation in sulfate aerosols, highly concentrated aqueous solutions of sulfuric acid, to gain an understanding of their surface morphology. Specifically, our novel methodology includes proton transfer, internal rotation (for $\mathrm{H}_{2} \mathrm{SO}_{4}$, $\mathrm{HSO}_{4}{ }^{-}$), and electronic polarization, the latter described either classically or via the PM3 semiempirical method. The inclusions of proton transfer and electronic polarization constitute substantial advances on current molecular simulation methods used for the description of sulfate aerosols. 
The PM3 atomic parameters of $\mathrm{H}, \mathrm{O}$, and $\mathrm{S}$ have been reoptimized via simulated annealing to fit energetics, structures, and dipole moments of several gas phase complexes of the species present in sulfate aerosols, namely $\mathrm{H}_{2} \mathrm{O}, \mathrm{H}_{3} \mathrm{O}^{+}, \mathrm{H}_{2} \mathrm{SO}_{4}, \mathrm{HSO}_{4}^{-}$, and $\mathrm{SO}_{4}{ }^{2-}$. In addition, by fitting large swaths of potential energy surfaces of a series of complexes of sulfate and water species calculated via the reparameterized PM3 method, a classical, polarizable force field was also developed in order to quickly provide equilibrated configurations for $\mathrm{H}_{2} \mathrm{SO}_{4} / \mathrm{H}_{2} \mathrm{O}$ samples for subsequent use as starting points for the computationally more demanding PM3 quantum simulations.

A parallel algorithm has been implemented and tested for the MPP2 cluster, and simulations for the bulk and surface structures of sulfuric acid tetrahydrate $\mathrm{H}_{2} \mathrm{SO}_{4} \bullet 4 \mathrm{H}_{2} \mathrm{O}$ and sulfuric acid dihydrate $\mathrm{H}_{2} \mathrm{SO}_{4} \bullet 2 \mathrm{H}_{2} \mathrm{O}$, representative of stratospheric sulfate aerosols, have been performed. Analyses of quasi-equilibrated configurations for the bulk mixtures of $\mathrm{H}_{2} \mathrm{SO}_{4} \bullet 4 \mathrm{H}_{2} \mathrm{O}$ and $\mathrm{H}_{2} \mathrm{SO}_{4} \cdot 2 \mathrm{H}_{2} \mathrm{O}$ at $300 \mathrm{~K}$ yield molar percentages for the $\mathrm{H}_{2} \mathrm{SO}_{4} / \mathrm{HSO}_{4}{ }^{-} / \mathrm{SO}_{4}{ }^{2-} / \mathrm{H}_{2} \mathrm{O} / \mathrm{H}_{3} \mathrm{O}^{+}$species consistent with those derived from thermodynamic and spectroscopic models, thus validating our methodology. Nearly equilibrated surface simulations for both the $\mathrm{H}_{2} \mathrm{SO}_{4} \bullet 4 \mathrm{H}_{2} \mathrm{O}$ and $\mathrm{H}_{2} \mathrm{SO}_{4} \cdot 2 \mathrm{H}_{2} \mathrm{O}$ species show increased presence of molecular species at the surface compared with bulk simulations. These findings are in line with our modelling of heterogeneous reactions at the surface of sulfate aerosols, where acid catalysis is provided by a molecule of $\mathrm{H}_{2} \mathrm{SO}_{4}$ embedded at the surface of a water layer.

\section{References}

Bianco, R and JT Hynes. 2004. "A Theoretical Study of the H2SO4+H2O -> HSO4-+H3O+ Reaction at The Surface Of Aqueous Aerosols.” Theoretical Chemistry Accounts (111) 182-187.

Donaldson DJ, AR Ravishankara, and DR Hanson. 1997. "Detailed Study of Hocl+Hcl->Cl-2+ $\mathrm{H}_{2} \mathrm{O}$ In Sulfuric Acid." Journal of Physical Chemistry A (101:26) 4717-4725.

Johnson, JK. 1999. "Reactive Canonical Monte Carlo.” Advances in Chemical Physics (105) 461-481.

Morita, A and JT Hynes. 2000. "A Theoretical Analysis of the Sum Frequency Generation Spectrum of the Water Surface." Chemical Physics (258) 371-390.

Morita, A and JT Hynes. 2002. "A Theoretical Analysis of the Sum Frequency Generation Spectrum of the Water Surface. II. Time-Dependent Approach.” Journal of Physical Chemistry B (106:3) 673-685.

Wang, TX and DW Margerum. 1994. "Kinetics of Reversible Chlorine Hydrolysis - TemperatureDependence and General Acid Base-Assisted Mechanisms.” Inorganic Chemistry (33:6) 1050-1055.

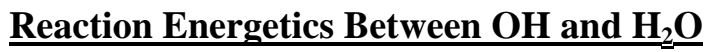

One of the most important free radical oxidants in the atmosphere is $\mathrm{OH}$ radical. It is responsible for the major oxidation processes that are removing volatile organic materials emitted in the atmosphere. A major question that has been recently raised is what is the oxidation capacity of the atmosphere. The answer to this question depended on whether the abundance of $\mathrm{OH}$ is known.

There have been several field studies directed at the measurement of the $\mathrm{OH}$ abundances, and these studies are revealing that the budget of $\mathrm{OH}$ in the atmosphere cannot be fully understood based on all 
the present state of known chemistry from laboratory gas-phase measurements. This has raised new questions of whether there is a heterogeneous route for the removal of $\mathrm{OH}$.

Laboratory studies for the uptake of $\mathrm{OH}$ by water surfaces indicate that there is little interaction of an $\mathrm{OH}$ radical with a water surface. However, recent MD studies from the group of Tobias (Roeselova et al. 2004 ) indicate that $\mathrm{OH}$ impinges on water surface, selectively binding to the water. Results from these studies have been called into question because of the inaccuracy of the molecular potential used to describe the interaction of the $\mathrm{OH}$ radical with a water molecule. In order to give an accurate empirical potential, we have been working on developing a new empirical potential for the $\mathrm{OH}-\mathrm{H}_{2} \mathrm{O}$ system using coupled cluster theory.

Potential energy surface scans have been determined using the CCSD(T) theory with large polarizable basis sets such as the Dunning augmented correlation consistent basis set (aug-cc-pVTZ basis set). The potential energy surfaces are currently being fitted to several model empirical potentials to capture the key features describing the essential interactions between $\mathrm{OH}$ radical and $\mathrm{H}_{2} \mathrm{O}$. The potential energy curves are outlined in Figures 11 through 14. The validity of the $\operatorname{CSSD}(\mathrm{T})$ energies was determined via judiciously chosen multi-reference configuration interaction calculations.
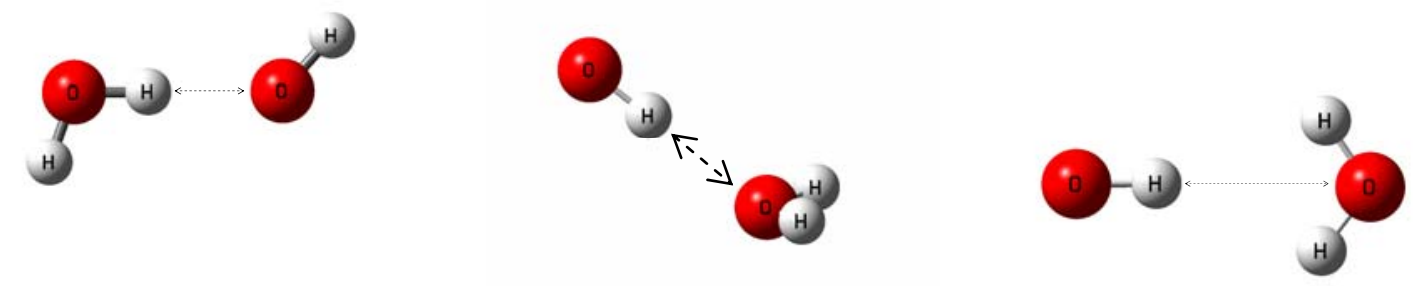

Figure 11. Geometry corresponding to PES scans (left to right) \#1, \#2, \#3.

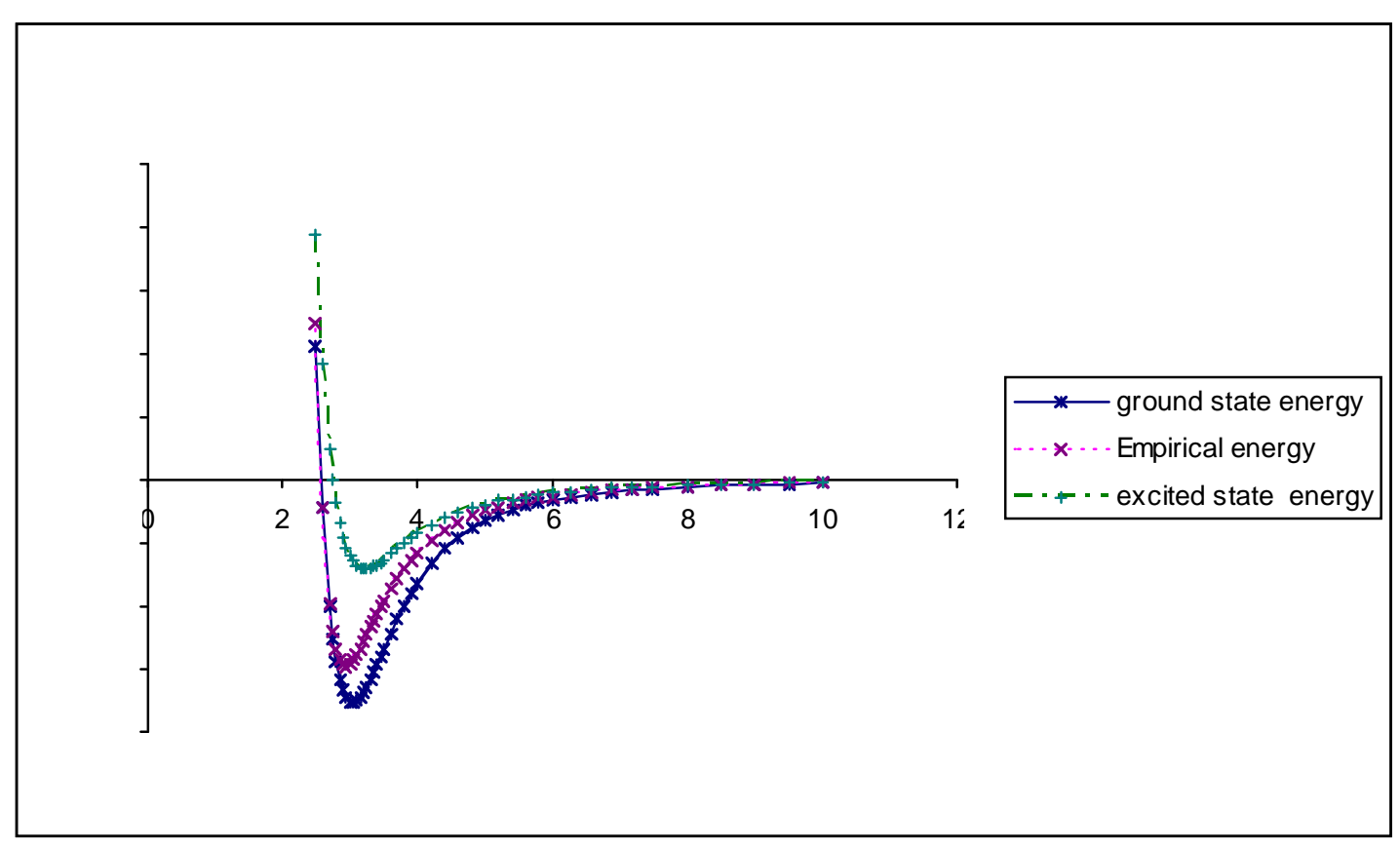


Figure 12. Potential Scan \#1. Interaction Energy vs. intermolecular O-O distance for the ground and excited state by $\operatorname{CCSD}(\mathrm{T})$ calculations and TTM2-R model empirical potential.

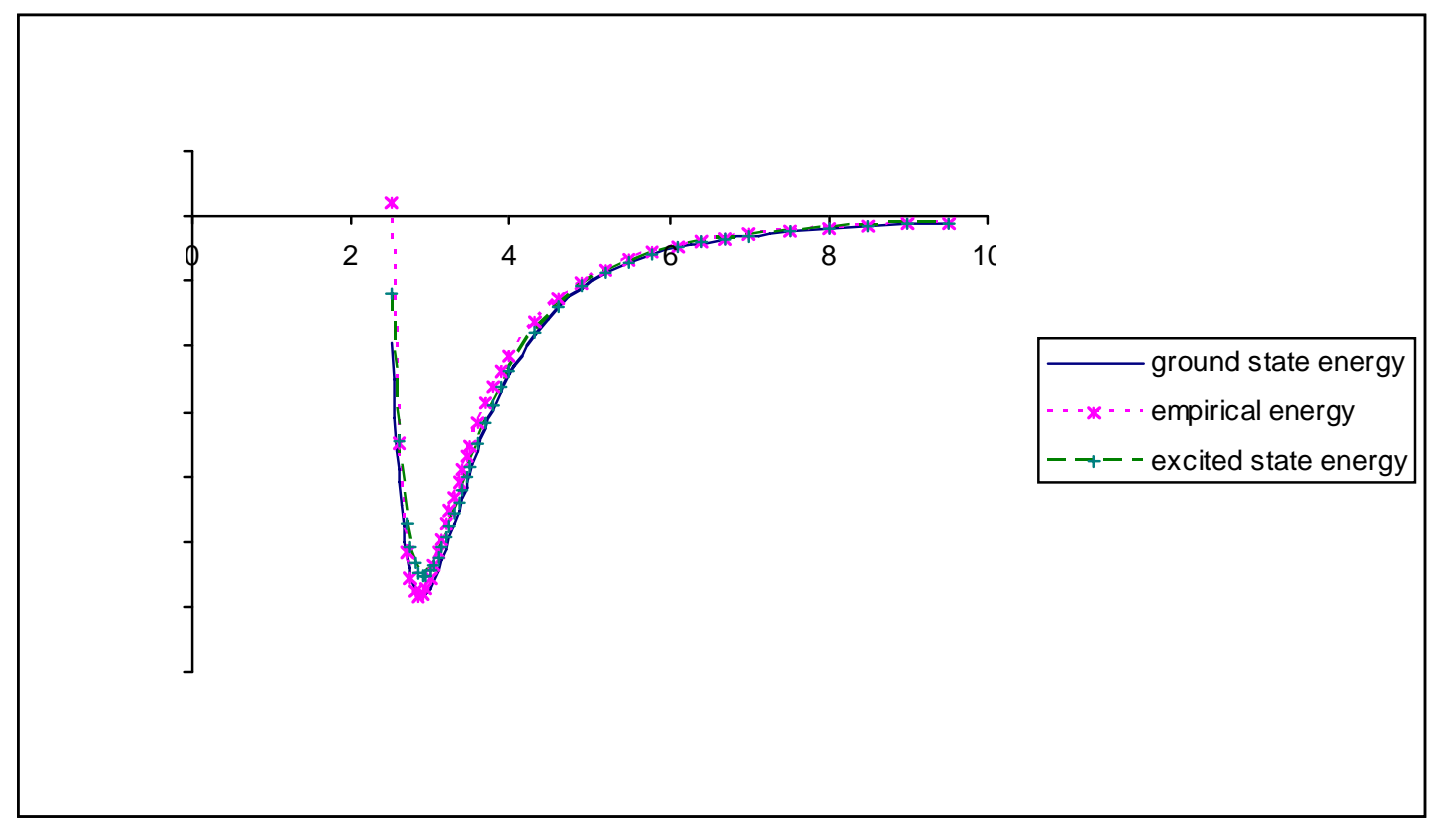

Figure 13. Potential Scan \#2. Interaction Energy vs. intermolecular O-O distance for the ground and excited state by $\operatorname{CCSD}(\mathrm{T})$ calculations and TTM2-R model empirical potential.

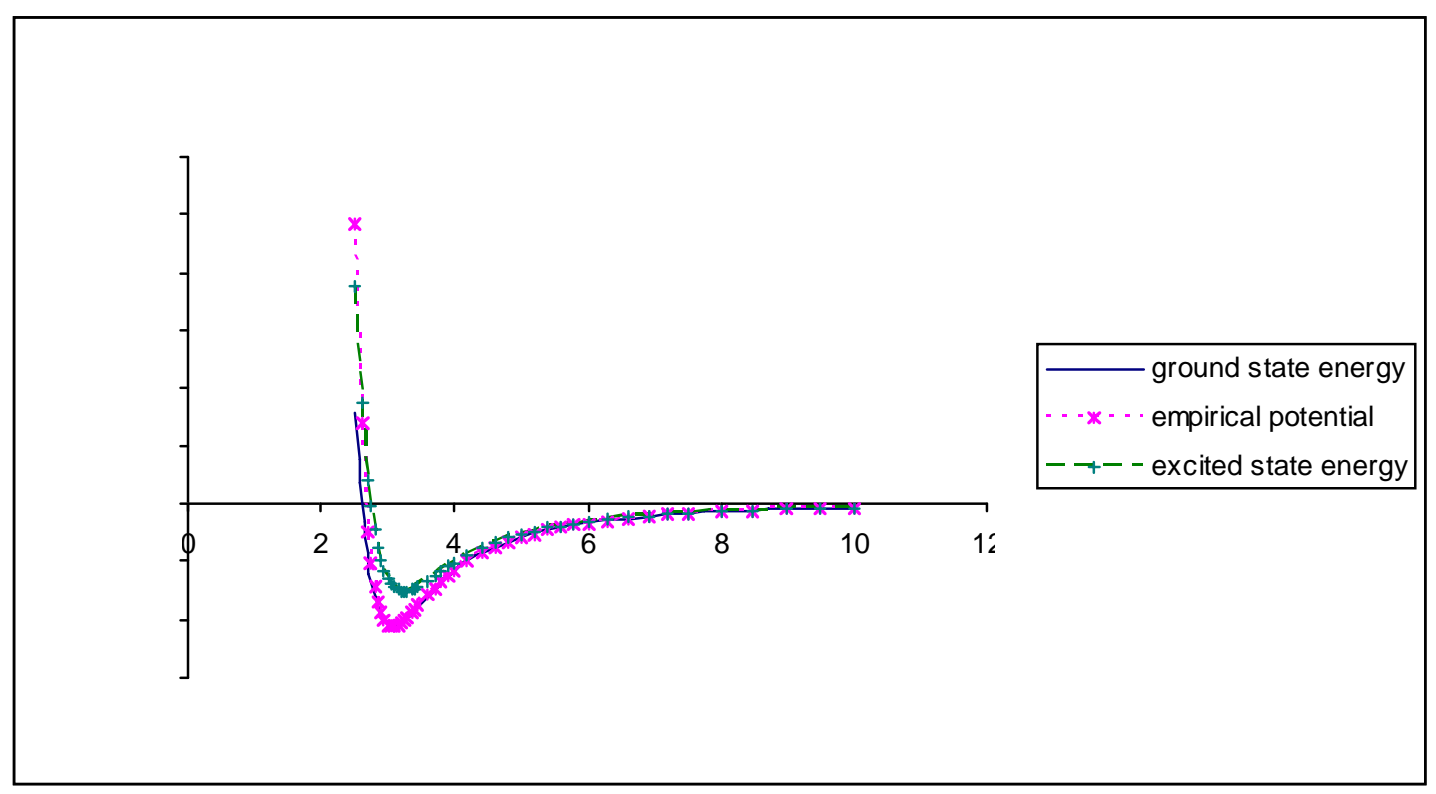

Figure 14. Potential Scan \#3. Interaction Energy vs. intermolecular O-O distance for the ground and excited state by $\operatorname{CCSD}(\mathrm{T})$ calculations and TTM2-R model empirical potential. 


\section{Reference}

Roeselova, M, J Vieceli, LX Dang, BC Garrett, and DJ Tobias. 2004. "Hydroxyl Radical at the AirWater Interface.” Journal of the American Chemical Society 126(50):16308-16309, DOI:

$10.1021 / \mathrm{ja} 045552 \mathrm{~m}$.

\section{List of Publications Resulting from This Work}

Kathmann, SM, GK Schenter, and BC Garrett. 2004. "Multicomponent Dynamical Nucleation Theory and Sensitivity Analysis." Journal of Chemical Physics (120:19) 9133-9141.

Kathmann, SM, GK Schenter, and BC Garrett. 2004. "Dynamical Nucleation Theory: Understanding the Role of Aqueous Contaminants." Proceedings of the $16^{\text {th }}$ International Conference on Nucleation and Atmospheric Aerosols, Eds. M Kasahara And M Kulmala, Kyoto University Press.

Kathmann, SM, GK Schenter, and BC Garrett. 2005. "Ion-Induced Nucleation: The Importance of Chemistry." Physical Review Letters, 94, 116104

Kathmann, SM, GK Schenter, and BC Garrett. 2004. "Dynamical Nucleation Theory: Understanding the Role of Aqueous Contaminants." Aerosol Research.

Schenter, GK, SM Kathmann, and BC Garrett. 2002. "Equilibirum Constant for Water Dimerization: Analysis of the Partition Function for a Weakly Bound System." Journal of Physical Chemistry A (106:8) 1557-1566.

Schenter, GK, SM Kathmann, and BC Garrett. 2002. "Dynamical Benchmarks of the Nucleation Kinetics of Water.” Journal of Chemical Physics (116:10) 4275-4280.

Kathmann, SM, GK Schenter, and BC Garrett. 2002. "Understanding the Sensitivity of Nucleation Kinetics: A Case Study on Water.” Journal of Chemical Physics (116:12) 5046-5057.

Garrett, BC, SM Kathmann, and Schenter, GK. 2003. "Thermochemistry and Kinetics of Evaporation and Condensation for Small Water Clusters." Water in Confining Geometries, Springer-Verlag, V Buch, and JP Devlin, Springer, New York.

Morita, A and JT Hynes. 2000. "A Theoretical Analysis of the Sum Frequency Generation Spectrum of the Water Surface." Chemical Physics (258) 371-390.

Morita A and JT Hynes. 2002. "A Theoretical Analysis of the Sum Frequency Generation Spectrum of the Water Surface. II. Time-Dependent Approach.” Journal of Physical Chemistry B (106:3) 673-685.

Bianco R and JT Hynes. 2004. "A Theoretical Study of the $\mathrm{H}_{2} \mathrm{SO}_{4}+\mathrm{H}_{2} \mathrm{O} \rightarrow \mathrm{HSO}_{4}{ }^{-}+\mathrm{H}_{3} \mathrm{O}^{+}$Reaction at the Surface of Aqueous Aerosols." Theoretical Chemistry Accounts (111) 182-197.

Fanourgakis, GS, E Aprá, and SS Xantheas. 2004. "High-Level Ab Initio Calculations for the Four LowLying Families of Minima Of $\left(\mathrm{H}_{2} \mathrm{O}\right)_{20}$. I. Estimates of MP2/CBS Binding Energies and Comparison with Empirical Potentials." Journal of Chemical Physics (121:6) 2655-2663. 
Fanourgakis, GS, E Aprá, W Dejong and SS Xantheas. 2005 . "High-Level Ab Initio Calculations for the Four Low-Lying Families of Minima of $\left(\mathrm{H}_{2} \mathrm{O}\right)_{20}$. II. Spectroscopic Signatures of the Dodecahedron, Fused Cubes, Face-Sharing Pentagonal Prisms, and Edge-Sharing Pentagonal Prisms Hydrogen Bonding Networks." Journal of Chemical Physics (122:13) 134304.

Fanourgakis, GS and SS Xantheas. 2006 "The Flexible, Polarizable, Thole-Type Interaction Potential for Water (TTM2-F) Revisited." Journal of Physical Chemistry A 110 (11) 4100-4106

Lagutschenkov, A, GS Fanourgakis, G Niedner-Schatteburg, and SS Xantheas. "The Spectroscopic Signature of the "All-Surface" to "Internally Solvated" Structural Transition in Water Clusters in the N=17-21 Size Regime.” Journal of Chemical Physics (122:19) 194340.

Kirov, MV, GS Fanourgakis, and SS Xantheas. “TTM2.1 'Strong-Weak-Effective-Bond' (SWEB) Discrete Model for the Combinatorial Optimization of Polyhedral Water Clusters: Validation from Electronic Structure Calculations and Discovery of a New Lowest Energy Isomer of the Pentagonal Dodecahedron (H2O) ${ }_{20}$ Cluster." Journal of Chemical Physics (submitted March 9, 2005).

\section{List of presentations resulting from this work}

Kathmann, SM. 2004. "Dynamical Nucleation Theory: Understanding the Role Of Aqueous Contaminants." $16^{\text {th }}$ International Conference On Nucleation And Atmospheric Aerosols 2004, July 2630, 2004, Kyoto University, Kyoto, Japan.

Kathmann, SM. 2003. "Consequences of Molecular Interactions in Nucleation." $21^{\text {st }}$ International Conference on Photochemistry, Special Session on Atmospheric Chemistry and Spectroscopy, July 26-31, 2003, Kyoto, Japan. [Invited Speaker]

Kathmann, SM. 2003. "Consequences of Molecular Interactions In Dynamical Nucleation Theory." $77^{\text {th }}$ ACS Colloid And Surface Science Symposium, June 5, 2003, Atlanta, GA.

Kathmann, SM. 2003. "Molecular Interactions in Dynamical Nucleation Theory." The Gordon Research Conference on Atmospheric Chemistry, September 21, 2003, The Big Sky Resort, Big Sky, Montana. [Poster]

Kathmann, SM. 2003. "Understanding the Relevance of Nucleation to Aerosol Radiative Forcing." Chemical, Structure and Dynamics Group, October 15, 2003, Pacific Northwest National Laboratory.

Kathmann, SM. 2002. "Solvation Thermodynamics of Small Ionic Water Clusters Relevant to Nucleation.” American Chemical Society Meeting, August 18-22, 2002, Boston, MA. [Invited Speaker]

Hynes, JT. 2002. "Heterogeneous Reactions on Stratospheric Ice and Sulfate Aerosols." American Chemical Society $223^{\text {rd }}$ National Meeting, Orlando, FL. [Invited Speaker]

Hynes, JT. 2002. Journes Des Ecoles Doctorales Carnot (Bourgogne) Et Pasteur (Franche-Comt), Besancon, FR. [Invited Speaker]

Hynes, JT. 2002. Societ Vaudoise Sciences Naturelles, Lausanne, CH. [Invited Speaker] 
Hynes, JT. 2002. French Group on Kinetics and Photochemistry in the Gas Phase, Paris, FR. [Invited Speaker]

Hynes, JT. 2002. IV International Conference, International Society for Theoretical Chemical Physics, Paris, FR. [Keynote Speaker]

Hynes, JT. 2003. Institut De Recherche Sur Les Systemes Atomiques Et Moleculaires Complexes, Toulouse, FR. [Invited Speaker]

Hynes, JT. 2003. Groupe De Recherche "Ice." Les Houches, FR. [Invited Speaker]

Hynes, JT. 2004. Symposium on Physics and Chemistry of the Atmosphere, American Physical Society Meeting, Montreal, Canada. [Invited Speaker]

Hynes, JT. 2004. Symposium on Computations for Environmental Chemistry, American Chemical Society Meeting, Anaheim, CA. [Invited Speaker]

Hynes, JT. 2004. Gordon Research Conference on Computational Chemistry, New Hampshire. [Invited Speaker]

Hynes, JT. 2004. Hirschfelder Prize in Theoretical Chemistry Lectures, Chemistry Department, University of Wisconsin, Madison, WI. [Invited Speaker (one of three)]

Hynes, JT. 2004. NSF Mathematical and Physical Sciences Workshop, Arlington, VA. [Plenary Lecture]

Morita, A. 2004. "Time Correlation Theory Of Sum Frequency Generation Spectra." 227th ACS National Meeting, March 28-April 1, 2004, Anaheim, CA.

Morita, A. 2002. "Theory and Simulation of Sum Frequency Generation Spectroscopy." 2nd Supercomputer Workshop, March 26-27, 2002, Okazaki, Japan. [In Japanese]

Morita, A. 2003. "Non-Empirical Analysis of SFG Spectroscopy Using Molecular Dynamics and Electronic Structure Calculations." Nagoya RCMS (Research Center For Materials Science) Workshop on SFG Spectroscopy, March 13-14, 2003, Nagoya, Japan. [In Japanese]

Morita, A. 2003. "Time-Dependent Theory of SFG Spectroscopy." 58th National Meeting of the Physical Society of Japan Symposium Frontiers in Surface Multiphoton Spectroscopy, March 28-31, 2003, Sendai, Japan. [In Japanese]

Morita, A. 2003. "Theoretical Analysis of Sum Frequency Generation Spectroscopy." Gordon Research Conference on Electronic Spectroscopy and Dynamics, July 6-11, 2003, Bates College, Lewiston, ME.

Morita, A. 2004. "Sum Frequency Generation Spectroscopy: Theory and Application to Surface Analyses." Okazaki Lectures: Winter School for Asian Students, December 6-9, 2004, Okazaki, Japan.

Bianco, R. 2004. "Theoretical Study Of The Surface And Bulk Structure Of Sulfate Aerosols." Annual APS March Meeting, Focus Session: Physics \& Chemistry of the Atmosphere, March 22-26, 2004, Montreal, Quebec, Canada. [Contributed] 
Bianco, R. 2004. "Sulfate Aerosols: Surface Structure And Heterogeneous Reactions." Workshop on Ice, Icy Surfaces, and Icy Particles, July 25-August 1, 2004, Telluride Science Research Center, Telluride, Colorado. [Invited]

Bianco, R. 2004. "Theoretical Studies of the Structure and Heterogeneous Reactions of Stratospheric Sulfate Aerosols." 228th National ACS Meeting, Liquids and Liquid Interfaces Symposium, August 2226, 2004, Philadelphia, PA. [Invited]

\section{List of significant methods/routines or codes developed with a brief}

\section{Theoretical analysis of Sum frequency Generation spectra}

Sum Frequency Generation (SFG) has been growing into a powerful surface analysis technique, especially for surfaces of atmospheric interests in ambient conditions. We have developed two theoretical methods to compute a surface SFG spectrum, based on either energy and/or time-dependent representations, and have first applied them to the water surface. These methods successfully reproduced the experimental spectrum via $a b$ initio molecular orbital and molecular dynamics calculations, and yielded a spectrum assignment stemming from the simulated microscopic surface structure.

\section{Monte Carlo simulation of sulfate aerosols}

We have formulated a biased variant of the Reactive Monte Carlo (RxMC) (Johnson et al. 1994) method, the Proton Transfer RxMC (PT-RxMC), which preserves the local hydrogen-bonding network by selecting a reactive complex with the reactants hydrogen-bonded, instead of selecting the reactants in separate locations as in RxMC (Johnson 1999). The reactive trial move results into a product complex, with the products also hydrogen-bonded, with minimal disruption of the original hydrogen-bonded network. In PT-RxMC simulations, the potential energy can be calculated via either a newly derived classical, polarizable force field or a re-parameterized PM3 semiempirical method (Stewart 1989). A FORTRAN code was developed to optimize the 65 atomic parameters of $\mathrm{H}, \mathrm{O}, \mathrm{N}$, and $\mathrm{S}$ to reproduce key energetic and structural properties of gas-phase species and complexes relevant to concentrated aqueous solutions of sulfuric acid. The code involved the interfacing of a simulated annealing routine to the GAMESS quantum chemistry package to run semiempirical calculations in parallel on the MPP2 cluster. A FORTRAN code was written to implement the PT-RxMC methodology to run in parallel on the MPP2 cluster.

\section{$\underline{\text { References }}$}

Johnson JK, AZ Panagiotopoulos, and KE Gubbins. 1994. "Reactive Canonical Monte-Carlo - A New Simulation Technique for Reacting or Associating Fluids." Molecular Physics (81:3) 717-177.

Johnson, JK. 1999. "Reactive Canonical Monte Carlo.” Advances in Chemical Physics (105) 461-481.

Stewart, JJP. 1989. "Optimization of Parameters for Semiempirical Methods. 1 Method." Journal of Computational Chemistry (10:2) 209-264. 